\title{
Case study: energy audit and implementation at the Russell Medical Center
}

\author{
D. F. Dyer \& C. O’Mary \\ Department of Mechanical Engineering, \\ Auburn University, Alabama, USA
}

\begin{abstract}
An energy evaluation at Russell Medical Center in Alexander City, Alabama was undertaken by the senior author as a part of a senior design class at Auburn University. Eight students (Chase O'Mary as their group leader) worked for eight months performing energy evaluations for all parts of the system. Based on their findings, recommendations for changes to reduce energy use and cost were made throughout the period. The largest savings were found in the following areas: Use of free cooling, consolidating chillers and boilers, better control of outside air, eliminating simultaneous heating and cooling, temperature reset, cooling tower optimization, setback in unoccupied zones, and control of evaporation from heated therapy pools. Partial implementation of these recommendations resulted in more than an actual 23\% reduction in natural gas usage and a $40 \%$ reduction in electric usage. Detailed results from all these areas are presented. This project is being continued until present. Current focus is on determining causes for not sustaining initial improvements and better understanding of impediments to full implementation of recommendations as well as an update on the current status of the project.
\end{abstract}

Keywords: energy audit, HVAC, chillers, boilers, cooling towers.

\section{Introduction}

Russell Medical Center is a progressive, not-for-profit, acute care facility comprising a large multi-building hospital [a central hospital (154,000 square feet), an adjacent cluster of three professional buildings (122,000 square feet), and a cancer center (14,000 square feet)] located in Alexander City, Alabama. 
The annual energy costs and water costs associated with operating the hospital are as follows:

Electricity: $\$ 442,000$

Natural Gas: $\$ 274,000$

Water and Sewage: $\$ 33,000$

A group of eight senior mechanical engineering students from Auburn University were assigned to a project to help the medical center reduce these costs. The students working under Professor Dyer logged more than 1000 man hours of engineering testing and analysis from August 2009 to May 2010 aimed at achieving this cost reduction objective.

The information subsequently documented in this paper describes the findings and results of this engineering effort.

\section{Problem statement}

As noted in the introduction it is desired to find opportunities to reduce energy and water costs for the Russell Medical Center. These opportunities can be broadly categorized in two areas: 1 . Actions that require a change in operation with little capital expenditure, and 2. Actions that require replacement and additions to equipment requiring significant capital expenditure. Those actions requiring little cost were almost immediately implemented while the remaining opportunities are being phased in as money becomes available-much of it from the cost savings requiring little capital expenditure!

\section{Project scope}

The project was to perform an energy audit at the Russell Medical Center facilities located in Alexander City, Alabama. The facilities studied for this project include the main hospital area which consists of an east and west wing, the three professional office buildings, and a cancer center. The majority of work was dedicated to the main hospital. The areas that were considered in order to reduce facility operating costs include HVAC systems such as the two natural gas fire tube boilers, the two water cooled and two air cooled chillers, the cooling tower, twenty air handler units, and lighting. Also water usage such as waste and make up water usage was analyzed along with hot water usage and the energy required.

The deliverables are to collect accurate usable data for analysis to find cost saving potentials which could be realized by making operating and equipment changes. These actions are to be analyzed in terms of potential energy savings and equipment requirements/costs. If additional equipment is justifiable, that equipment must be designed and/or specified. All of these findings are provided to management for implementation.

The audit began with looking at the primary equipment for generation of cooling and heating. Then opportunities to save energy in transporting heating and cooling were examined. Finally, the use of heating and cooling processes was analyzed. 


\section{Savings potential for HVAC generation equipment}

\subsection{Chillers}

Russell Medical Center utilizes Trane CenTraVac water cooled, centrifugal chillers, and Trane air cooled, screw type chillers to cool water to supply the chilled water loop. The main hospital building is supplied by two water cooled, centrifugal chillers with 350 and 400 ton capacities. The surrounding professional buildings are on a separate chilled water loop which is supplied by two 120 ton capacity air cooled chillers, and two 80 ton capacity backup air cooled units. The facility also utilizes a plate and frame heat exchanger to supply cool water when outside temperature conditions permit. When this project began, the facility was not able to operate the plate and frame heat exchanger.

\subsubsection{Raise chill water supply temperature}

The main hospital requires a low chilled water supply temperature for its critical surgery and air handler units. The rest of the facility calls for normal chilled water supply temperatures three to four degrees higher than the critical area supply temperature. Initially the chillers were not plumbed with isolation valves. This required both chillers to make the lower supply water temperature in order to meet demand for surgery which is inefficient. In order to remedy this problem, it was recommended that isolation valves be installed so that each chiller could be separated and its supply water temperature set according to its requirement. This allows the critical areas to be supplied with the lower water temperature and the rest of the facility to be supplied with a more energy efficient higher supply temperature. Table 4.2 in reference [2] shows that the percent compressor power savings that can be achieved through raising the condenser water temperature by $1 \mathrm{~F}$ is approximately $1.6 \%$. In some cases the chilled water could be reset by $6 \mathrm{~F}$ giving nearly a $10 \%$ saving. In addition, providing a supply temperature lower than the required temperature results in reheating the air using additional boiler fuel. Installation of these valves allowed a saving of approximately $\$ 32,000$ per year considering both the heating and cooling cost reduction obtained.

\subsubsection{Interconnect chillers}

Russell Medical Center has two separate chilled water loops, one for the main hospital and one for the professional buildings. They are supplied by the chillers described in section 4.1. Evaluation of the facility cooling load shows a surplus of cooling capacity especially with the two water cooled chillers in the main hospital. Further assessment shows that the water cooled centrifugal chillers operate about thirty percent more efficiently than the air cooled screw type chillers in the professional buildings. This study shows that significant energy savings could be achieved if the two separate chilled water loops were interconnected to create a unified chill water loop. The recommended new unified chill water loop uses the more economical water cooled chillers as the main units and the air cooled units as backups. The less efficient air cooled chillers could then be shut down. The water cooled chillers have enough surplus 
capacity to supply the professional buildings with cold water for most of the cooling season with backup, if necessary, by the air cooled chillers. This modification also allows the professional buildings to use the plate and frame heat exchanger when outside conditions permit, as well as create chiller redundancy for the entire facility. Implementation of this recommendation would require a capital investment of approximately $\$ 114,000$ and create and save approximately $\$ 25,600 / \mathrm{yr}$. This proposal has not yet been implemented, but action is being taken by Russell Medical Center senior management to secure the funds for this project.

\subsubsection{Reduce condenser water temperature into chillers}

Russell Medical Center's water cooled chillers employ a cooling tower to cool the condenser water. The effect of reducing condenser water inlet temperature is very similar to that of raising the chilled water temperature which reduces the temperature lift that must be supplied by the chiller which in turn reduces operating costs. Effectively lowering the inlet condenser water temperature without causing operational problems varies according to chiller design and operating conditions. In the case of Russell Hospital both chillers require that the lowest condenser water temperature allowable is about $72 \mathrm{~F}$. Initially, both chillers were operating at approximately $82 \mathrm{~F}$ allowing room for a temperature decrease of $10 \mathrm{~F}$. Table 4.1 in reference [2] shows that the percent compressor power savings that can be achieved through lowering the condenser water temperature by $10 \mathrm{~F}$ is $11 \%$. This saving can be achieved more than $50 \%$ of the year (say 4000 hours) because the wet bulb temperature allows the cooling tower to achieve this temperature. The average cooling load in this period is approximately 350 tons. The electrical savings based on an electrical rate of $\$ .08 / \mathrm{kw}-\mathrm{hr}$ amounts to approximately $\$ 11,000$ per year.

\subsubsection{Monitor cooling tower makeup water separately to avoid sewage charges}

Cooling towers use evaporative cooling to cool condenser water. This means that a significant amount of water is lost due to evaporation and must be made up. Facilities are often charged sewer charges based on the amount of water that they use because it is assumed that it must be disposed via the sewer. However, this is not the case with a cooling tower. Approximately 7,300,000 US gallons of water are evaporated by the Russell Medical Center cooling towers annually. .Makeup water to the cooling tower is metered daily. The makeup water replaces both water evaporated from the cooling tower and water discharged as "blow down" to maintain the quantity of dissolved solids at an acceptable level. By metering the amount of blow-down water that is discharged to sewer, the amount of evaporated water can be calculated. The hospital is currently charged for sewer on evaporated water at a rate of $\$ 2.72$ per 1000 gallons. It was recommended that Russell Medical Center apply for cooling tower water exemption. That would save approximately $\$ 20,000$ per year in sewer charges. However, the City water authority is requiring Russell Hospital to run a separate water line from the street in order to exempt sewage charges. An approximate 1000 foot line is required 
and must traverse parking areas. As a result the cost of implementation is high and is estimated to be $\$ 20,000$. The project has not been implemented waiting on further negotiations with the City.

\subsubsection{Use free cooling}

Currently, the medical facility has in place a plate and frame heat exchanger to provide indirect cooling of chilled water using condenser water from the cooling tower. The wet bulb temperature must be low enough to allow cooling of the condenser water temperature to approximately $45 \mathrm{~F}$. Due to a lack of controls on the cooling tower to prevent freezing and lack of isolation valves on the chillers to prevent problems of changeover between the two modes of cooling, this system was not operable when the audit project began. Recommendations to remedy these problems were made and subsequently implemented. It is estimated that free cooling can be used for approximately 1500 hours per year replacing an average of 300 tons. This results in a potential saving of $\$ 36,000$ annually. This recommendation is implemented at an approximate cost of $\$ 10,000$.

\section{Saving potential for HVAC transport systems}

\subsection{Air handler fans}

Currently the air handlers units use constant speed fans to supply air to the occupied space. These constant speed fans accomplish the job but can't be throttled back in times of lower demand to reduce energy consumption. It was recommended that Russell Medical Center look into variable frequency drive fans to replace the constant speed fans currently in operation. Approximately 500 Hp should be retrofitted with variable speed drives. This proposal comes with a savings of $\$ 72,000$ annually and has an initial installed cost of $\$ 66,000$. The project is currently underway.

\section{Saving potential for HVAC processes}

\subsection{Air handlers}

Both the main hospital and professional buildings employ air handlers to heat and cool the air that is supplied to the occupied zone. The engineering team performed a full examination of the operating conditions of all the air handling units. The investigation revealed that simultaneous heating and cooling was occurring within some units. This is a very wasteful operating condition. Air was being warmed up by air handler preheat coils prior to being cooled by the chilled water cooling coil. This condition creates an unnecessary heating cost and greater cooling cost. It was found to be caused by stuck valves and HVAC control system issues. This recommendation is partially implemented. Elimination of simultaneous heating and cooling has a potential to reduced energy costs by approximately $\$ 24,000$ per year. 
The air handler investigation also showed an opportunity to reduce energy costs by optimizing outside air usage. Ideally during the peak demand of the cooling and heating season one would aim to reduce outside air to minimum acceptable levels in order to reduce the total heating or cooling load, and during off peak times when outside conditions are favorable, use as much outside air as possible in order to utilize free cooling via outside air. Russell Medical Center's initial operating conditions allowed for some reduction in outside air usage during peak times and some free cooling by introducing outside air during offpeak times. However, some control system issues will have to be resolved in order to fully utilize free cooling. It was recommended that outside air levels be lowered on four units by twenty percent. This action requires careful monitoring of building air pressure to prevent infiltration and carbon dioxide levels to insure proper ventilation. Outside air optimization at Russell Medical Center was projected to reduced energy costs by approximately $\$ 9,000$. This proposal has been partially implemented and will be fully implemented when control system issues can be resolved.

It was also recommended that occupancy sensors be installed in order to control room temperature set points. Currently room temperature set points are controlled by the occupant. Energy can be saved both in cooling and heating by being able to create an unoccupied economy mode for areas that are unoccupied for a significant amount of time. This recommendation has a capital cost of approximately $\$ 17,000$ and results in a projected return of $\$ 5,000$ per year. It has not currently been implemented. At the same time, the occupancy sensors should be used to control lighting resulting in a small additional saving.

\subsection{Swimming pool}

Indoor pool covers can significantly reduce swimming pool heating costs. Swimming pools lose energy primarily by evaporation. The evaporation and heat loss to the room requires room ventilation to control indoor humidity. The ventilated air also must be conditioned, which adds to the energy costs. Pool covers on indoor pools not only can reduce evaporation but also the need to ventilate indoor air and replace it with unconditioned outdoor air. In addition, the exhaust fans can be turned off when an indoor pool is covered saving even more energy. There is also a savings associated with the sewage charge for the water saved by the cover and the savings for the makeup water needed.

The evaporation rate for the two pools is about 19 gallons per hour. At 5,840 covered hours per year, a savings of approximately $\$ 300$ dollars per year in sewage charges and approximately $\$ 150$ dollars per year in makeup water is obtained. The energy savings as described above amounts to approximately $\$ 7,000$ per year giving a total savings of approximately $\$ 7,500$ per year.

A pool cover costs of $\$ 13,500$ dollars for this application. This project has not currently been implemented. 


\section{Summary}

Table 1 gives a summary of the project recommendations, potential savings, and project costs. Many of the lower capital cost projects have been implemented and other larger cost projects are underway. The total projects have a savings approximately equal to the total project costs yielding a simple payback of approximately 1 year. At the end of the project, actual billing records compared to the same month in the previous year show that the use of electricity was down by $40 \%$ and the use of gas was down by $23 \%$. This result is a graphic indication of the success gained by the energy audit described herein and its implementation.

Table 1: $\quad$ Summary savings.

\begin{tabular}{|c|c|c|}
\hline & $\begin{array}{c}\text { Savings/ } \\
\text { yr }\end{array}$ & $\begin{array}{l}\text { Implementation } \\
\text { Cost, } \$\end{array}$ \\
\hline \multicolumn{3}{|l|}{ Actions Requiring Little Capital cost } \\
\hline $\begin{array}{l}\text { Eliminating Air Handler Simultaneous } \\
\text { heating/cooling }\end{array}$ & $\$ 24,000$ & nil \\
\hline Reducing Outside Air & $\$ 9,000$ & nil \\
\hline Lowering Condenser Water & $\$ 11,000$ & nil \\
\hline Raise Supply Temperature & $\$ 32,084$ & nil \\
\hline \multicolumn{3}{|l|}{ Actions Requiring Significant Capital cost } \\
\hline $\begin{array}{l}\text { Eliminating Air Cooled Chillers by } \\
\text { interconnecting chilled water loop from } \\
\text { Hospital to Professional building }\end{array}$ & $\$ 25,600$ & $\$ 114,000$ \\
\hline Sewer Exemption for Cooling Tower & $\$ 20,000$ & $\$ 20,000$ \\
\hline Indoor Pool Cover & $\$ 7,500$ & $\$ 13,500$ \\
\hline Variable Frequency Drive Fan Savings & $\$ 72,000$ & $\$ 66,000$ \\
\hline $\begin{array}{l}\text { Occupancy Sensors to control unoccupied } \\
\text { zone conditions }\end{array}$ & $\$ 5,000$ & $\$ 17,000$ \\
\hline $\begin{array}{l}\text { Implement free cooling using existing plate } \\
\text { and frame heat exchanger }\end{array}$ & $\$ 36,000$ & $\$ 10,000$ \\
\hline Total savings & $\$ 241,500$ & $\$ 240,500$ \\
\hline
\end{tabular}

\section{References}

[1] O’Mary, C., Russell Hospital Energy Audit, Report on Senior Design Project, Department of Mechanical Engineering, Auburn University, Alabama 2010.

[2] Dyer, D.F. \& Maples, G., HVAC Efficiency Improvement, Boiler Efficiency Institute: Auburn, Alabama 2009. 